\title{
OPTIMIZATION OF AN URBAN TRANSPORT SYSTEM ON THE CONDITION OF DIFFERENT GOALS OF MUNICIPAL AUTHORITIES, OPERATORS AND PASSENGERS
}

\author{
Mark Koryagin $^{1}$, Vladimir Katargin ${ }^{2}$ \\ ${ }^{1}$ Kemerovo State Agriculture Institute, Kemerovo, Russia \\ ${ }^{2}$ Siberian Federal University, Krasnoyarsk, Russia
}

Submitted 14 March 2014; resubmitted 26 September 2014; accepted 3 March 2015

\begin{abstract}
A control system of urban passenger transport is considered. The system participants are a passenger flow, a transport operator and municipal authorities. The participants' strategies include a travel mode choice, a frequency of public transport service, and a road capacity. Objective functions are transport costs, public transport profit, road costs, and travel time. The passenger flow heterogeneity is based on the value of time that has an exponential distribution. The total costs of passenger flow depend on the probability of the travel mode choice. The dependence between travel time, roads capacity, and traffic is based on Greenshields model. The authorities' objective consists of travel time and road costs, which can be changed by the road capacity. The game theoretic approach is applied to describe the control system. The existence of Nash equilibrium for coalition-free games for two (the passenger flow and the authorities and three (with addition of public transport) players is proved. The characteristics of urban passenger transport were studied based on a numerical example.
\end{abstract}

Keywords: mode choice; passenger transportation; road capacity; optimal control; game theory.

\section{Introduction}

Development of transport science has led to the conclusion that the increase of roads capacity is not the only possible way to solve the traffic problems of cities.

Many theoretical and practical examples show that the construction of additional public roads may have no effect or even negative influence on travel time. In particular, Downs-Thomson paradox indicates that the increase of roads capacity leads to congestion. As the capacity increases, the passengers shift from the public transport into cars, the public transport operator loses the quality, which, in turn, shifts additional passengers into cars. Therefore, the process of increasing roads capacity may lead to degradation of public transport, increasing traffic, and congestion (Downs 1992).

To solve the problem the authorities use restrictions and prohibition for car users, which decrease traffic. However, such solution reduces the decision-making freedom and it decreases the quality of life too. It is generally preferred to use the active system theory (Burkov, Enaleev 1994), i.e. the authorities create conditions for a useful passenger decision-making (by improving the public transport quality).
The main reason of the paradox is that the travel mode choice must be respected. Therefore, mathematical models will be significantly complicated.

In the review (Hollander, Prashker 2006) a lot of research is considered in which game theoretic models of transport system are classified according to the set of participants (private company and travellers, authorities and travellers, private company and authorities, authorities between themselves, and private companies among themselves). Such classification was suggested for transportation system (Evans 1987). The paper introduced participants 'potential passengers', 'operators' and 'public authority', but statement of the problem was presented as non-game model. Concepts of non-cooperative game are used for the solution of the conflict of interest between participants. The urban transportation system (Koryagin 2011) represented by a set of private companies (which explore a set of routes), authorities and a set of passenger flows (which make travel mode choice). The existence of Nash equilibrium was proved for the system. The paper (Bell, Wichiensin 2012) took into consideration the dependence between the traffic and the travel time. In the (Zhang et al. 2008) was used either a set of participants:

Corresponding author: Mark Koryagin

E-mail: markkoryagin@yandex.ru 
traveller, node and arc, which were presented as a road user, an intersection and a roadway segment.

It is necessary to join both classifications. In this paper, the mathematical model of urban transport system consists of roads, public transport operator and passenger flow, with their strategies and goals. Such approach allows to construct more complicated models of urban transportation system by considering the interests of passengers, public transport and authority that manages the road.

\section{System of Urban Transport}

The structure of urban passenger transport system can be represented by subsystems 'authorities', 'passenger flow' and 'public transport operator'. All the participants influence each other, so the functions of profit and costs depend on all parameters.

In published models (Koryagin 2011), the travel time was static, i.e. the mode choice did not have an influence on travel time by car or by public transport. In this paper such influence is taken into consideration by introducing a participant 'municipal authorities' (the authorities manage subsystem 'road'). The participant strategy is road capacity (or travel time) and the goal is the reducing of the road costs and travel time.

Urban system exchanges parameters amid participants as shown in the scheme (Fig. 1). The passenger flow uses the travel time by car and by public transportation for a travel mode choice. The choice generates the transit passenger flow and car traffic. The public transportation interval depends on bus velocity and transit passenger flow. The road capacity depends on traffic (both car and bus) and determines the travel time by car and bus velocity.

\subsection{Subsystem 'Passenger Flow'}

Subsystem 'passenger flow' determines transit passenger flow and car traffic. It is difficult to imagine that every passenger would carry out the calculations of different characteristics of travel, build a model and solve it by the numerical method. However, the behaviour of the passenger flow is possible to be described mathematically.

The passenger flow looks for a proportion between using a private car and the public transportation. The goal function of the passenger flow is the total travel costs (travel time, waiting time and transport costs).

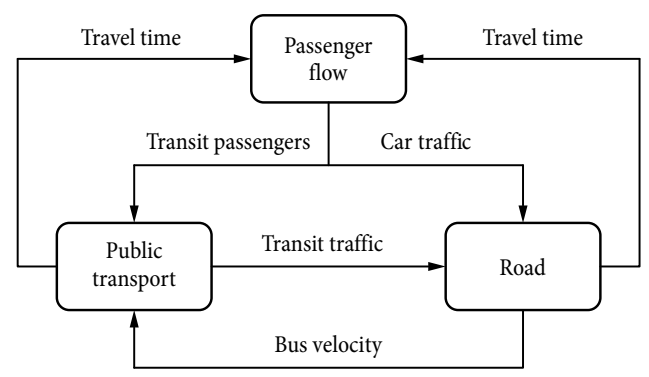

Fig. 1. Urban transport system: passenger flow, public transport and road mutual influence
If the distance between origin and destination is large, then passengers will choose between to drive or to go by public transport. Travelling by car is more expensive than by public transportation, but requires less time. Therefore, the part of passenger flow with low value of time will use public transport.

The main parameters determinate the travel mode choice: $\beta$ - fare at the public transport; $t$ - time of traveling by car; $\Delta t$ - the difference between the travel time by the public transport and car disregarding the time of waiting for the public transport; $\mu$ - frequency of the public transport (transit) (Poisson flow); $c$ - costs of car using (the costs of traveling by car are assumed to exceed the public transport fare $c>\beta$ ); $\gamma^{\prime}$ - average value of time; $p$ - the probability of car use for transportation which everybody determines in terms of economic utility.

Usually travel mode choice models are based on logit-models (Horowitz et al. 1986). But those models do not have a decision-making process. Therefore, researchers' used models are based on the value of time dispersion. Usually, the value of time is described by the uniform distribution (Dodgson, Katsoulacos 1988), but really the value of time is changed over a wide range. Suppose that the cost of travel time were described by the exponential distribution (Koryagin 2008). Let $\gamma^{\prime}$ be the value of time, which divides the passengers by travel mode (if the value of time is less than $\gamma^{\prime}$, traveller chooses a bus, else a car), then:

or:

$$
p=\exp \left(-\frac{\gamma^{\prime}}{\gamma}\right)
$$

$$
\gamma^{\prime}=-\gamma \ln (p)
$$

The average value of time (conditional mathematical expectation) for public transport is:

$$
\begin{aligned}
& \int_{0}^{\gamma^{\prime}} \frac{x}{\gamma} \exp \left(-\frac{x}{\gamma}\right) d x \\
& \int_{0}^{\gamma^{\prime}} \frac{1}{\gamma} \exp \left(-\frac{x}{\gamma}\right) d x \\
& \frac{\gamma+\gamma p \ln (p)-\gamma p}{1-p} \int_{0}^{-\gamma \ln (p)} \frac{x}{\gamma} \exp \left(-\frac{x}{\gamma}\right) d x= \\
& 1-p
\end{aligned}
$$

The dispersion of travel time by bus or car is disregarded in the model. The mathematical expectation of travel time is used. Therefore, average costs per travel on the public transport consist of the travel time $t=\Delta t$, waiting time $\frac{1}{\mu}$ and fare at the public transport $\beta$ :

$$
\frac{\gamma+\gamma p \ln (p)-\gamma p}{1-p}\left(\frac{1}{\mu}+t+\Delta t\right)+\beta
$$

In addition, the average value of time of using a car (Koryagin 2008) is:

$$
\frac{\int_{\gamma^{\prime}}^{\infty} \frac{x}{\gamma} \exp \left(-\frac{x}{\gamma}\right) d x}{\int_{\gamma^{\prime}}^{\infty} \frac{1}{\gamma} \exp \left(-\frac{x}{\gamma}\right) d x}=
$$




$$
\begin{aligned}
& \frac{1}{p} \int_{-\gamma \ln (p)}^{\infty} \frac{x}{\gamma} \exp \left(-\frac{x}{\gamma}\right) d x= \\
& \gamma-\gamma \ln (p) .
\end{aligned}
$$

The average costs per travel by car is:

$$
(\gamma-\gamma \ln (p)) t+c
$$

The purpose of the passenger flow is the minimization of total travel costs changing parameter $p$. The total passengers' costs per travel consist of the sum of the costs of travelling by car Eq. (2) with probability $p$ and public transport Eq. (1) with probability $1-p$ :

$$
\begin{aligned}
& G(t, p, \mu)=(\gamma+\gamma p \ln (p)-\gamma p)\left(\frac{1}{\mu}+t+\Delta t\right)+ \\
& \beta(1-p)+(\gamma p-\gamma p \ln (p)) t+c p \rightarrow \min _{p} .
\end{aligned}
$$

Claim 1. Costs function per travel $G(t, p, \mu)$ is convex downward function in the parameter $p$.

Proof. The first derivative of the total costs per travel is as follows:

$$
\gamma \ln (p)\left(\frac{1}{\mu}+\Delta t\right)+(c-\beta)
$$

The second derivative is as follows:

$$
\gamma \frac{1}{p}\left(\frac{1}{\mu}+\Delta t\right) \geq 0 \text {. }
$$

Therefore, the $G(t, p, \mu)$ is convex downward function in the parameter $p$.

By equating derivate (4) to zero, we get the optimal probability of car use:

$$
p=\exp \left(-\frac{(c-\beta)}{\gamma\left(\frac{1}{\mu}+\Delta t\right)}\right)=\exp \left(-\frac{\mu(c-\beta)}{\gamma(1+\Delta t \mu)}\right) .
$$

The probability of travels by the public transport is as follows:

$$
1-\exp \left(-\frac{\mu(c-\beta)}{\gamma(\mu \Delta t+1)}\right)
$$

\subsection{Subsystem 'Public Transport'}

The strategy of public transport operator is the public transport frequency $\mu$. The operator may increase the number of transit passengers by increasing $\mu$ (decreasing waiting time), but expenses increases too.

Ridership on public transport is the product of the intensity of the passenger flow $\lambda$ on the probability of choice of public transport Eq. (6):

$$
\lambda\left(1-\exp \left(-\frac{\mu(c-\beta)}{\gamma(\mu \Delta t+1)}\right)\right) \text {. }
$$

The profit (the difference between income and expenses) is:

$$
H_{1}(\mu)=\lambda \beta\left(1-\exp \left(-\frac{\mu(c-\beta)}{\gamma(\mu \Delta t+1)}\right)\right)-\alpha \mu \rightarrow \max ,
$$

where: $\alpha$ - the cost of round trip of the public transport.
Claim 2. The function $H_{1}(\mu)$ is convex upward in the parameter $\mu$.

Proof. The first derivative of the $H_{1}(\mu)$ is as follows:

$$
\begin{aligned}
& \lambda \beta \exp \left(-\frac{(c-\beta)}{\gamma \Delta t}\right) \frac{(c-\beta)}{\gamma(\mu \Delta t+1)^{2}} \times \\
& \exp \left(-\frac{c-\beta}{\gamma \Delta t}\left(\frac{1}{\mu \Delta t+1}\right)\right)-\alpha .
\end{aligned}
$$

The second derivative (7) is as follows:

$$
\begin{aligned}
& -\lambda \beta \exp \left(-\frac{(c-\beta)}{\gamma \Delta t}\right)\left(\frac{(c-\beta) \Delta t}{\gamma(\mu \Delta t+1)^{3}}+\frac{(c-\beta)^{2}}{\gamma^{2}(\mu \Delta t+1)^{4}}\right) \times \\
& \exp \left(-\frac{c-\beta}{\gamma \Delta t}\left(\frac{1}{\mu \Delta t+1}\right)\right)<0 .
\end{aligned}
$$

The second criterion of efficiency of public transport operator is minimization of the travel (waiting) time (1) and spending on public transport:

$$
H_{2}(\mu)=\frac{\gamma(1+p \ln (p)-p)}{\mu}+\alpha \mu \rightarrow \min .
$$

One of the major constraints is the restriction on capacity of a bus $q$ :

$$
\lambda(1-p) \leq q \mu \text {. }
$$

\subsection{Subsystem 'Road'}

Municipal authorities have to find optimal parameters of road infrastructure (subsystem roads) which depend on traffic intensity.

Traffic flow theory is greatly developing but most of traffic flow models have been made based on fundamental diagram of Greenshields (Kerner 2009).

The higher traffic intensity leads to worse traffic congestion. Average traffic speed reduction is well described by a simple Greenshields model (Greenshields et al. 1935):

$$
v=v_{0}\left(1-\frac{\rho}{\rho_{j}}\right)
$$

where: $v_{0}$ - constant (free) speed; $\rho_{j}$ - jam density, i.e. the density when traffic is so heavy that it is at a complete standstill (vehicles per unit distance), $\rho$ average traffic density (vehicles per unit distance).

The density depends on the average traffic speed and the average rate of flow of vehicles $\lambda^{\prime}$ (vehicles per unit time):

$$
\rho=\frac{\lambda^{\prime}}{v} \text {. }
$$

Note that the total flow of personal and public transport can be expressed by the following formula:

$$
\lambda^{\prime}=\lambda p+d \mu
$$

where: $d$ is a coefficient that expresses bus vehicles in terms of equivalent passenger car.

Thus, Greenshields formula is written as follows:

$$
v=v_{0}\left(1-\frac{\lambda^{\prime}}{v \rho_{j}}\right) \text {, }
$$


using the dependence:

$$
v=\frac{l}{t}
$$

the formula is obtained:

$$
\frac{l}{t}=v_{0}\left(1-\frac{t \lambda^{\prime}}{l \rho_{j}}\right)
$$

The choice of variable influences further calculations. In this case, a travel time $t$ is used as variable, so we express the road capacity $\rho_{j}$, that depending on the variable $t$ (i.e. the travel time determines the road capacity):

$$
\rho_{j}(t, p, \mu)=\frac{\lambda^{\prime} t^{2} v_{0}}{l\left(v_{0} t-l\right)}=\frac{(\lambda p+d \mu) t^{2} v_{0}}{l\left(v_{0} t-l\right)} .
$$

Claim 3. Function $\rho_{j}(t, p, \mu)$ is convex downward in the parameter $t$.

Proof. The first derivative of $\rho_{j}(t, p, \mu)$ is as follows:

$$
\frac{\lambda^{\prime} v_{0}\left(t^{2} v_{0}-2 t l\right)}{l\left(v_{0} t-l\right)^{2}}<0 \text {. }
$$

The second derivative of $\rho_{j}(t, p, \mu)$ is as follows:

$$
\frac{2 \lambda^{\prime} v_{0} l}{\left(v_{0} t-l\right)^{3}}>0 \text {. }
$$

Thus, the road capacity Eq. (11) is convex downward function in the travel time.

Passenger flow' costs consist of travel time on cars and the public transport:

$$
p \lambda t \gamma+(1-p) \lambda\left(t+\Delta t+\frac{1}{\mu}\right) \text {. }
$$

The road costs (construction and maintenance) depends on the road capacity Eq. (11), the road length and the coefficient $\delta$ (costs per unit of distance per unit of capacity per unit of time):

$$
\rho_{j} l \delta=\frac{l \delta(\lambda p+d \mu) t^{2} v_{0}}{l\left(v_{0} t-l\right)} .
$$

The cities costs consist of passengers costs Eq. (12) and road costs Eq. (13) is:

$$
\begin{aligned}
& F_{1}(t, p, \mu)=p \lambda t \gamma+(1-p) \lambda\left(t+\Delta t+\frac{1}{\mu}\right)+ \\
& \frac{(\lambda p+d \mu) \delta t^{2} v_{0}}{\left(v_{0} t-l\right)} \rightarrow \min .
\end{aligned}
$$

A public transport allows to transit a lot of passengers at lower cost. Public transport requires less road infrastructure per passenger than car. Therefore, a more complex criterion is considered - the sum of travel time Eq. (3), transport expenses $\alpha \mu$ and $c \lambda p$, and roads costs (the fare at the public transport are not taken into account because it is redistributed fees between passengers and transport operator):

$$
\begin{aligned}
& F_{2}(t, p, \mu)=\lambda(\gamma+\gamma p \ln (p)-\gamma p)\left(\frac{1}{\mu}+t+\Delta t\right)+ \\
& \alpha \mu+\lambda(\gamma p-\gamma p \ln (p)) t+c \lambda p+ \\
& \frac{(\lambda p+d \mu) \delta t^{2} v_{0}}{\left(v_{0} t-l\right)} \rightarrow \min .
\end{aligned}
$$

Claim 4. Function $F_{2}(t, p, \mu)$ is convex downward in the parameters $t, \mu$.

Proof. Function (15) consists of several parts. Linear summands:

$$
\lambda(\gamma p-\gamma p \ln (p)) t \gamma+c p+\alpha \mu
$$

Summand:

$$
\lambda(\gamma+\gamma p \ln (p)-\gamma p)\left(\frac{1}{\mu}+t+\Delta t\right)
$$

consists of two terms with coefficient: hyperbole in $\mu$ and linear in $t+\Delta t$.

Finally:

$$
\frac{(\lambda p+d \mu) l \delta t^{2} v_{0}}{l\left(v_{0} t-l\right)}
$$

can be described as:

$$
g(\mu) f(t)
$$

where: according to Claim 3, $f(t)$ is convex downward and $g(\mu)=\lambda p+d \mu$ is linear; it is easy to check that the product functions $g(\mu) f(t)$ will also be a convex downward function.

The sum of convex and linear functions is a convex function.

\section{Optimization of Urban Transport System}

Several formulations of the problem are considered. At first participant must define the set of strategies.

For the passenger flow it's probability of car use $p \in P, P=[0,1]$. For the transit it's the public transport frequency $\mu \in \mathrm{M}, M=[0, \bar{\mu}]$. The upper bound $\bar{\mu}$ may be defined from the following reason: the number of buses in the city must be limited. For road the strategy is travel time by car $t \in T, T=\left[\frac{l}{v_{0}}, \bar{t}\right]$. The lower bound is minimal travel time (travel with maximal velocity $v_{0}$ ), the upper bound $\bar{t}$ may be limited for the road (traffic must be less than road capacity).

\subsection{The First Statement of the Problem}

Passenger flow minimizes the total passengers' costs per travel by variation of the probability of car use. The public transport maximizes the profit by variation of the public transport frequency. The authorities minimize Eq. (14) by variation of the travel time. Thus, the game with three participants is constructed.

Proposition 1. The game $\left\langle P, M, T,-G, H_{1},-F_{1}\right\rangle$ has a Nash equilibrium.

Proof. Consider the conditions of the Nash equilibrium existence theorem (Glicksberg 1952).

- Set of pure strategies of players is compact, convex and not empty. The condition is performed for sets $P, M, T$.

- Players payoff functions are quasiconcave in self strategies and continuous. Obviously, that the Eqs $(3,7,14)$ is continuous function in the $p, t, \mu$. 
The payoff functions Eqs $(3,7)$ are convex (Claim 1, 2). The function Eq. (14) consists of linear and convex summands (Claim 3) and convex too.

\subsection{The Second Statement of the Problem}

Passenger flow minimizes the total passengers' costs per travel by variation of the probability of car use. The public transport minimizes the waiting time and spending on public transport by variation of the public transport frequency. The authorities minimize Eq. (14) by variation of the travel time. Thus, the game with three participants is constructed.

Proposition 2. The game $\left\langle P, M, T,-G,-H_{2},-F_{1}\right\rangle$ has a Nash equilibrium.

The proof is trivial. Unlike Proposition 1, the convexity of Eq. (8) is required but the requirement is obviously satisfied.

\subsection{The Third Statement of the Problem}

Passenger flow minimizes the total passengers' costs per travel by variation of the probability of car use. The authorities minimize total costs of the passenger flow, the public transport and the road Eq. (15) by variation of the travel time and the public transport frequency. Thus, the game with two participants is constructed.

Proposition 3. The game $\left\langle P, M \times T,-G,-F_{2}\right\rangle$ has a Nash equilibrium.

The proof is trivial. The $F_{2}$ is convex downwards function (Claim 4).

\subsection{The Fourth Statement of the Problem}

The authorities minimize total costs of the passenger flow, the public transport and the road by variation of the travel time and the public transport frequency. The passengers' activity is used by Eq. (5). The probability of car uses $p$ on Eq. (15) must be substituted on Eq. (5). Therefore, the classical (not game) optimization statement will be constructed:

$$
\begin{aligned}
& F_{3}(t, \mu)=\alpha \mu+c \lambda \exp \left(-\frac{\mu(c-\beta)}{\gamma(1+\Delta t \mu)}\right)+ \\
& \lambda \gamma\left(1-\left(\frac{\mu(c-\beta)}{\gamma(1+\Delta t \mu)}+1\right) \exp \left(-\frac{\mu(c-\beta)}{\gamma(1+\Delta t \mu)}\right)\right) \times \\
& \left(\frac{1}{\mu}+t+\Delta t\right)+\lambda t \gamma \times \\
& \exp \left(-\frac{\mu(c-\beta)}{\gamma(1+\Delta t \mu)}\right)\left(1+\frac{\mu(c-\beta)}{\gamma(1+\Delta t \mu)}\right)+ \\
& \left(\lambda \exp \left(-\frac{\mu(c-\beta)}{\gamma(1+\Delta t \mu)}\right)+d \mu\right) \delta t^{2} v_{0} \\
& \frac{\left(v_{0} t-l\right)}{\ln (1)} \rightarrow \text { min. }
\end{aligned}
$$

All the statement is considered in the numerical example.

\section{Numerical Example}

All four statements of the problem are considered on the numerical example (it's named by 'Model 1', 'Model 2', 'Model 3' and 'Model 4'). The parameter changing shifts equilibrium point. Therefore, we research into how parameters influence the urban transport system for each control system. The characteristics of solution are probability of car use $p$, road capacity $\rho_{j}$, public transport frequency $\mu$, and total costs $F_{2}$.

Parameters of the models are considered for Krasnoyarsk city (Russia). Average number of lane 4 (two in each direction), average travel distance $10 \mathrm{~km}$ :

- the fare at the public transport $\beta=19$ roubles;

- the intensity of the passenger flow $\lambda=6000$ passengers per hour;

- the difference between the travel time by the public transport and car $\Delta t=0.1$ hour;

- the frequency of the public transport $\mu=7$ bus per hour;

- the costs of car using $c=100$ roubles (for $10 \mathrm{~km}$ );

- the average value of time $\gamma=200$ roubles per hour;

- the cost of round trip by the public transport $\alpha=$ 1500 roubles;

- the jam density $\rho_{j}=200$ cars per km;

- the coefficient expresses bus vehicles in terms of equivalent passenger cars $d=2$;

- the road costs $\delta=5$ roubles (the parameter was estimated as average road costs in Krasnoyarsk per year that is divided on the road capacity and amount of peak hours in a year).

We use coordinate descent with method of golden section for numerical solution. We have not proved the convergence of such simple approach for all parameters of the models, but the approach always led to optimal solution on our examples.

First of all the average value of time is different in cities or may be changed in the city (economic growth or reduction).

The travel time is the most important parameter in the models. High level of income leads to high level of motorisation and congestion (Fig. 2).

If the value of time increases, then a car will be a more attractive mode than the public transport (Fig. 3). However, city leads to a high level of motorization slowly (Model 4) or faster (Model 3). Such tendencies are shown for the road capacity (Fig. 4).

The public transport fare has more complicated influence on the value of time (Fig. 5). For the low level of the value of time, the frequency can increase (Model 1 and Model 4). In the low level of income, passengers are more sensitive to the mode choice. Model 3 leads to degradation of public transport. The optimal frequency (Model 4) must be greater than the equilibrium one.

The total costs (Fig. 6) will increase. However, mode in Model 3 gets better results than in Models 1 and 2 for upper level of income. 
The second parameter is the fare at the public transport. The Models 1-3 lead to obvious results: the optimal fare is zero (models do not consider passenger flow generation). The Model 1 shows more interesting results (Fig. 6). The characteristics are convex or concave on the fare (Fig. 7).

The car mode cost influences on public transport. The Model 2 leads to the development of public transport. However, with the low level of car costs public transport will degrade (only Model 4 has large frequency) - Fig. 8.

All models have identical trends when the passenger flow intensity is increasing: the probability of car use is decreasing, public transport frequency is increasing. It shows that for a small city, cars are more effective and for a big city, public transport is.

Numerical example shows that the public transport will work in all conditions, because passengers have different value of time, therefore catastrophic degradation of described public transport does not take place.

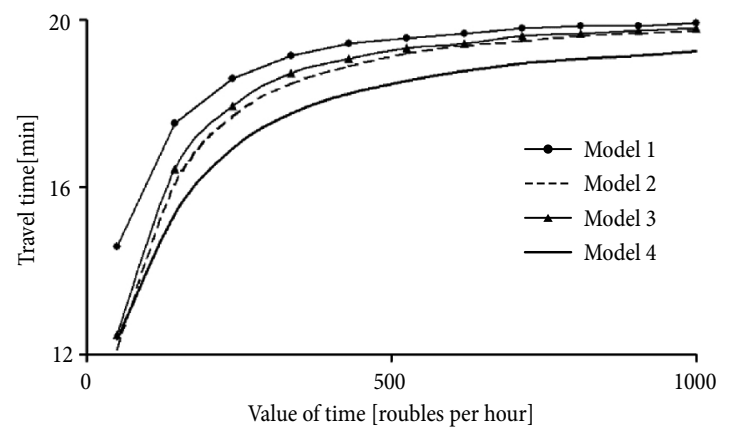

Fig. 2. Influence of value of time on time travelling by car

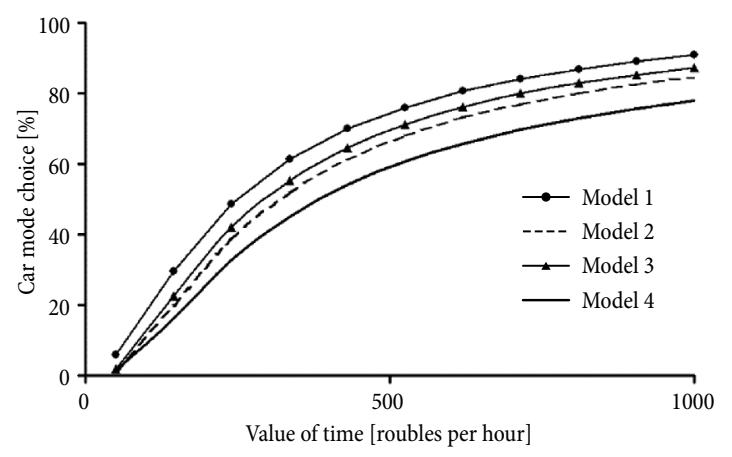

Fig. 3. Influence of value of time on probability of car use

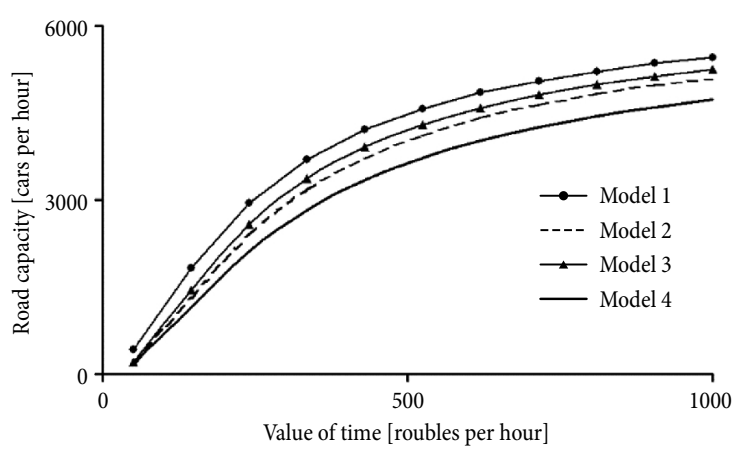

Fig. 4. Influence of value of time on road capacity
Table shows that both optimal road capacity and travel time increase (will be Downs-Thomson paradox). However, if the intensity of passenger flow increases, the road capacity and the travel time should have different trends.

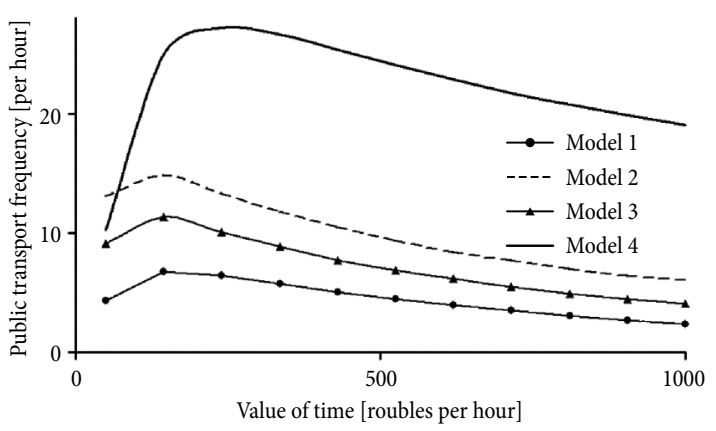

Fig. 5. Influence of value of time on public transport frequency

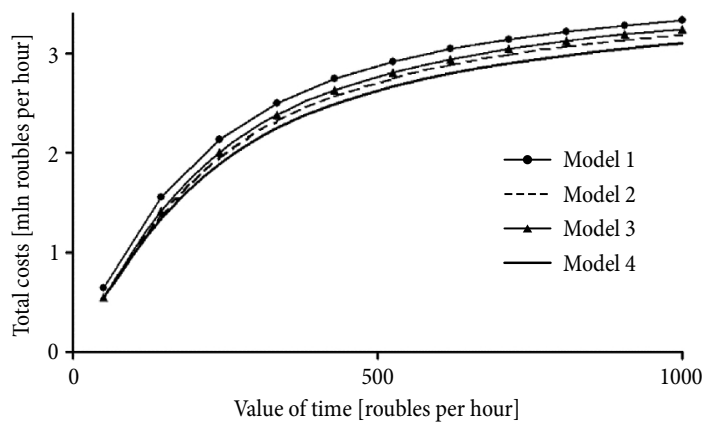

Fig. 6. Influence of value of time on total costs

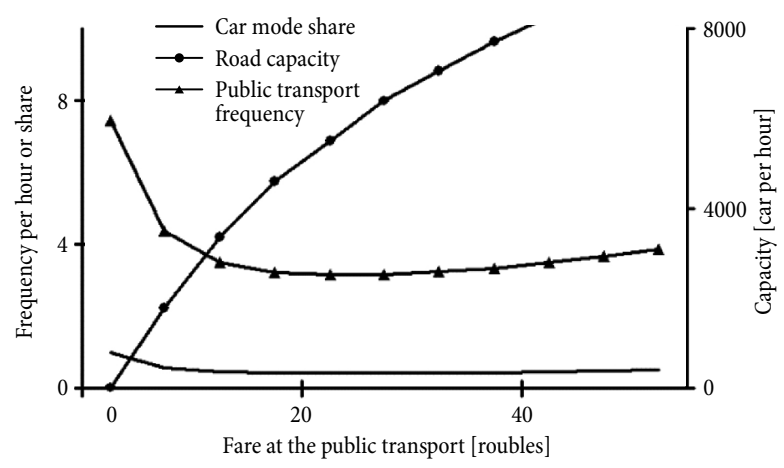

Fig. 7. Influence of fare at the public transport on characteristics of the Model 1

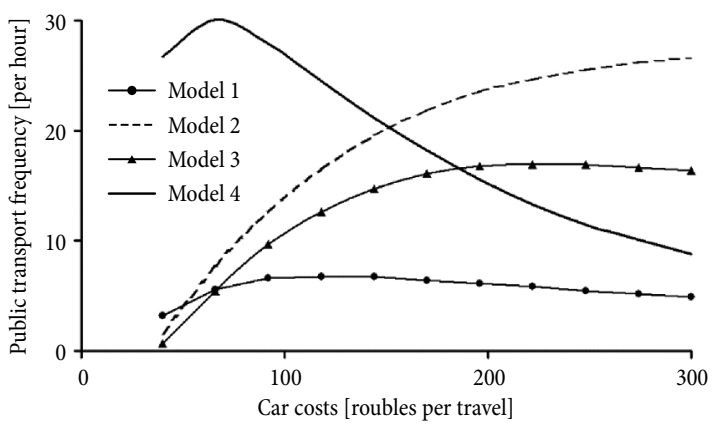

Fig. 8. Influence of car mode cost on public transport frequency 
Table. Travel time and road capacity changes, when parameter increase

\begin{tabular}{|l|c|c|c|c|}
\hline Statement & 1 & 2 & 3 & 4 \\
\hline Value of time & $\begin{array}{c}\text { both } \\
\text { increase }\end{array}$ & $\begin{array}{c}\text { both } \\
\text { increase }\end{array}$ & $\begin{array}{c}\text { both } \\
\text { increase }\end{array}$ & $\begin{array}{c}\text { both } \\
\text { increase }\end{array}$ \\
\hline $\begin{array}{l}\text { Intensity of } \\
\text { passenger flow }\end{array}$ & opposite & opposite & opposite & opposite \\
\hline $\begin{array}{l}\text { Fare at public } \\
\text { transport }\end{array}$ & $\begin{array}{c}\text { both } \\
\text { convex }\end{array}$ & $\begin{array}{c}\text { both } \\
\text { increase }\end{array}$ & $\begin{array}{c}\text { both } \\
\text { increase }\end{array}$ & $\begin{array}{c}\text { both } \\
\text { increase }\end{array}$ \\
\hline
\end{tabular}

The numerical example shows that Model 2 (Fig. 3) is better than Model 3 for low value of time, but worse for high value of time. In other words, public transportation agency and traffic agency in the developed countries must be united. Model 2 gives preference to public transport (Fig. 4), but Model 3 prefers to develop road infrastructure.

Next stage of research will be generalization of the given models for real-sized road network. The road network will be presented as a set of participants (road segments), besides passengers will consist of a set of passengers flow (between each origin and destination). It is important to understand whether the models are adequately in real situations or not. We wish to make an important note that it is impossible to find an optimal solution (Model 4) for a real-sized city, because largescale goal function will be non-convex. However, Models 1-3 allow to find Nash equilibrium in a few time. In addition, if equilibrium point will be close to optimal point then the suggested approach will have practical implications.

The following problems call for further investigations:

- taking into account other forms of public transport (which use dedicated way, such as light rail, trolleybus, BRT, metro);

- taking into account the trips generation (choice of destination or trip withdrawal);

- optimizing of city planning (parking, parks, shops, job location, housing);

- generalization of the model to the case of the real-sized road network;

- cooperation with practical scientists allow to implement models for calculating optimal parameters of the real cities.

The major goal of this research is the development of the model that can improve the quality of life by optimizing the citizens' mobility.

\section{Conclusions}

1) Three participants: the passenger flow, the public transport operator and the road are introduced. The strategies, the set of strategies and participants' goal functions are constructed.

2) The existence of Nash equilibrium is proved. Four statements of the problem are formulated as follows: - the first statement described poor nations, which cannot subsidy public transport (private company manages public transport);
- the second statement describes developing nations; in this case, traffic agency and public transportation operator are independent public organizations;

- the third statement describes developed nations; united agency manages both public transport and traffic;

- the fourth statement presents optimal (non-game) solution to the problem, but applicability of this approach is limited because it is a large-scale nonconvex problem.

3) The numerical example shows the influence of the parameters on the solution for each statement of the problem. The models predict further degradation of public transportation in Krasnoyarsk city (Russia) on condition of passengers income growth.

\section{References}

Bell, M. G. H.; Wichiensin, M. 2012. Road use charging and inter-modal user equilibrium: the Downs-Thompson paradox revisited, in O. Inderwildi, S. D. King (Eds.). Energy, Transport \& the Environment, 373-383. Available from Internet: http://dx.doi.org/10.1007/978-1-4471-2717-8_20

Burkov, V. N.; Enaleev, A. K. 1994. Stimulation and decisionmaking in the active system theory: review of problems and new results, Mathematical Social Sciences 27(3): 271291. http://dx.doi.org/10.1016/0165-4896(93)00739-H

Dodgson, J. S.; Katsoulacos, Y. 1988. Quality competition in bus services: some welfare implications of bus deregulation, Journal of Transport Economics and Policy 22(3): 263-281.

Downs, A. 1992. Stuck in Traffic: Coping with Peak-Hour Traffic Congestion. Brookings Institution Press and the Lincoln Institute of Land Policy. 224 p.

Evans, A. 1987. A theoretical comparison of competition with other economic regimes for bus services, Journal of Transport Economics and Policy 21(1): 7-36.

Glicksberg, I. L. 1952. A Further generalization of the Kakutani fixed point theorem, with application to Nash equilibrium points, Proceedings of the American Mathematical Society 3(1): 170-174. http://dx.doi.org/10.2307/2032478

Greenshields, B. D.; Bibbins, J. R.; Channing, W. S.; Miller, H. H. 1935. a study of traffic capacity, Highway Research Board Proceedings 14: 448-477.

Hollander, Y.; Prashker, J. N. 2006. The applicability of noncooperative game theory in transport analysis, Transportation 33(5): 481-496. http://dx.doi.org/10.1007/s11116-006-0009-1

Horowitz, J. L.; Koppelman, F. S.; Lerman, S. R. 1986. A SelfInstructing Course in Disaggregate Mode Choice Modeling. Washington, DC, US. 193 p.

Kerner, B. S. 2009. Introduction to Modern Traffic Flow Theory and Control: The Long Road to Three-Phase Traffic Theory. Springer. $265 \mathrm{p}$.

Koryagin, M. E. 2011. Ravnovesnye modeli sistemy gorodskogo passazhirskogo transporta $v$ usloviyah konflikta interesov. Novosibirsk: Nauka. 140 p. (in Russian).

Koryagin, M. E. 2008. Competition of public transport flows, Automation and Remote Control 69(8): 1380-1389. http://dx.doi.org/10.1134/S0005117908080109

Zhang, L.; Levinson, D.; Zhu, S. 2008. Agent-based model of price competition, capacity choice, and product differentiation on congested networks, Journal of Transport Economics and Policy 42(3): 435-461. 